\title{
Critically Evaluate the Capabilities of Ultrasonic Techniques Used for Tracing Defects in Laminated Composite Materials
}

\author{
Senan Thabet ${ }^{a}$, Yaser A. Jasim ${ }^{b}$, Thabit H. Thabit ${ }^{c^{*}}$ \\ ${ }^{a}$ Faculty of Computing, Engineering and Science, University of South Wales, Cardiff, UK \\ ${ }^{b}$ Department of Accounting, Cihan University-Erbil, Erbil, Iraq \\ $c^{*}$ Collage of Electronic Engineering, Ninevah University, Mosul, Iraq \\ *E-mail address: $\underline{\text { stc@englandmail.com }}{ }^{\text {a }}$, yaser.jasim@ $@$ cihanuniversity.edu.iq $^{\text {b }}$, thabit.acc@ gmail.com ${ }^{\text {c* }}$
}

Received date: 30.09 .2018

Accepted date: 31.10 .2018

ORCID numbers of authors:

0000-0003-0251-7364 ${ }^{a}, 0000-0003-3374-720 X^{b}, 0000-0003-2033-6110^{c}$

\begin{abstract}
A Non-Destructive Test (NDT) technique is the fundamental strategy to look at a large portion of the materials, composite materials specifically. There are an excessive number of NDT techniques to assess the materials, for example, Visual Inspection, Liquid Penetrate Inspection, Eddy-Current Inspection, Phased Array Inspection, Magnetic Particle Inspection and Ultrasonic Inspection. The report delineates the Ultrasonic Test (UT) research centre examination that was directed with the group number 5 in the University lab, a few references and resources are utilised as a part of this investigation to completely exhibit the applications and deformity traceability of UT in covered composites. The paper finishes up the examination with the capacities and restrictions of the two systems and prescribes techniques to endeavour lessening the confinements.
\end{abstract}

Keywords: Non-Destructive Testing, Ultrasonic Testing, and Composite Materials.

\section{Introduction}

Composite materials are a mix of two materials or more combined to get a specific basic properties, the blended materials don't break down totally in each other yet they act together as one strong material[1]. The reason for making composite materials is to get high pressure, low weight, fatigue resistance and corrosion resistance than the individual material. The request on composite materials has been expanded as the composite materials has expanded the execution and lessened the fuel utilisation particularly in aeronautics industry fields[2]. Since 60 years back Non-Destructive Test (NDT) has been in consistent advancement as it is the significant technique to decide and assess the composite materials[3]. In the most recent decades the vendors had an essential research for most composite materials to assess these sort of materials which are very surprising contrasted with ordinary materials[4]. The consolidated materials has supply the manufacturers with a one of a kind highlights that are inaccessible in typical materials. The designers advantage from the focal points offered by the composite materials that have light weight, hostile to consumption, high in opposition and incredible effectiveness proper for some applications in the mechanical area[5]. Because of 
the complex tiny structure of these composite NDT techniques has been connected as often as possible to look at these entangled materials[6].

Presently nowadays ultrasonic tasting devices has a standout amongst the most utilised equipment and many well-known procedures worked to perform NDT appraisal on composite materials utilised as a part of aeronautical industry[7]. Despite of the unnecessarily various sorts of NDT materials examination, ultrasonic methodology is one of the broad strategies. In this investigation we will centre around ultrasonic technique which are extensively using ultrasonic area equipment and makes it possible to choose any disfigurements in numerous sorts of materials[8]. For evaluating composite materials ultrasonic procedures are for the most part used. With only a solitary access surface ultrasonic instrument are perfect to be used with either point column or straight line testing methodologies[9].

\section{Discussion}

\subsection{Aims:}

To discover any deformities in the composite materials by utilizing non-destructive test (NDT), with the ultrasonic equipment to trace any defects in the composite materials.

\subsection{Objectives:}

- Investigate ultrasonic technique as None-destructive testing method performed to asses laminated composites.

- $\quad$ Analyze their capabilities and limitations in tracking defects in composite structures.

- $\quad$ For effective NDT experiments, it is important to understand the nature of the material being tasted for better results.

In this paper we will review the carbon fibre as the ultrasonic investigation is appropriate for these sort of composites. In 1878 Sir Joseph Wilson Swan delivered glaring lights with carbon strings. Carbon fibre produced using around ten layers squeezed together under high weight, vacuumed and a sap topping off. Carbon fibre composite is a high temperature obstruction, weightless and fatigue, corrosion resistance[6].

A contact technique is been connected to examine composite materials by phase array method moved over the tasted piece[2]. A specific measure of frequency could be applied. The surface ought to be perfect and smooth, a medium called couplant is performed between the test and the inspect material to beat the power scattering which exists when the sound waves travel between the test and the surface of the composite and to fill the minute holes giving an exceptionally smooth surface to the test of the ultrasonic hardware to movement on[3].

In aeronautical industry NDT strategy considered as a much solid procedure to distinguish and recognize the deformities that can seriously influence the composite structure prompts terrible catastrophe particularly in formula1, ocean, aeronautical industry and more[5].

A specific frequency will be connected and it can shift between $5 \mathrm{MHz}$ to $10 \mathrm{MHz}$ through a test which is inside partitioned in to 64 sections to have the capacity to cover as much it 
can[2]. This frequency will go through the composite make an interpretation of the outcome in to a diagram, frequency travelling would inverts if any deformity exists generally will bear on until the base surface of the composite, in the other word the information result of the ultrasonic device comes as a chart which would ready to clarified by the designers[1].

\subsection{Literature Review:}

Because of past examinations have exhibited that the specialist and the planners dependably battle and striving to give best, powerful and solid devices at least conceivable cost with a superior execution to deliver the most precise gear that the designers could depend on to give a more secure condition.

In 1929 and 1935 ultrasonic waves contemplated by Sokolov to identify metal items. In 1931 Mulhauser obtained a patent in ultrasonic wave by utilizing two transducers to uncover abandons in solids. Firestone and Simons (1940) (1945) separately enhanced pulse ultrasonic testing by utilising a pulse-echo method. Josef Krautkrämer and Karl Deutsch 1949 in Germany both began in changes without the learning of each other. Josef Krautkrämer and his sibling the physicists Herbert working in oscilloscopes field. Karl Deutsch a mechanical specialist and Hans-Warner Branscheid a radar professional who had got some additional specialised understanding amid the second world two. The ultrasonic devices has been exhibited by the two organisations and as yet contending each other up to this point nowadays $[10,11]$.

\subsection{Ultrasonic Testing (UT) Implementations in Composites:}

Notwithstanding the limitations of ultrasound testing system, this NDT strategy can give significant data to professionals while utilising them to assess composites[2]. At the point when UT is rehearsed on composites, it determines thickness estimations of composites and in addition mechanical deformities area and seriousness[1]. Broad inquires about and thinks about have been directed by a few organisations to comprehend the proliferation conduct of ultrasounds through laminated materials and its impact as shown in figure (1)[12].

In ultrasonic test devices, a sonic power is changed over from electrical power by methods for an equipment called a transducer (probe)[4]. The reason for a transducer is to transmit bunch of waves all through a test piece and get signals back to decide the state of a test composite[1]. As it were, pulse-echo ultrasound check uses high frequency to assess the separation by estimating it as far as time of flight[13]. To execute ultrasonic testing procedure on a test piece, there are three ultrasound testing basic techniques[14]. 


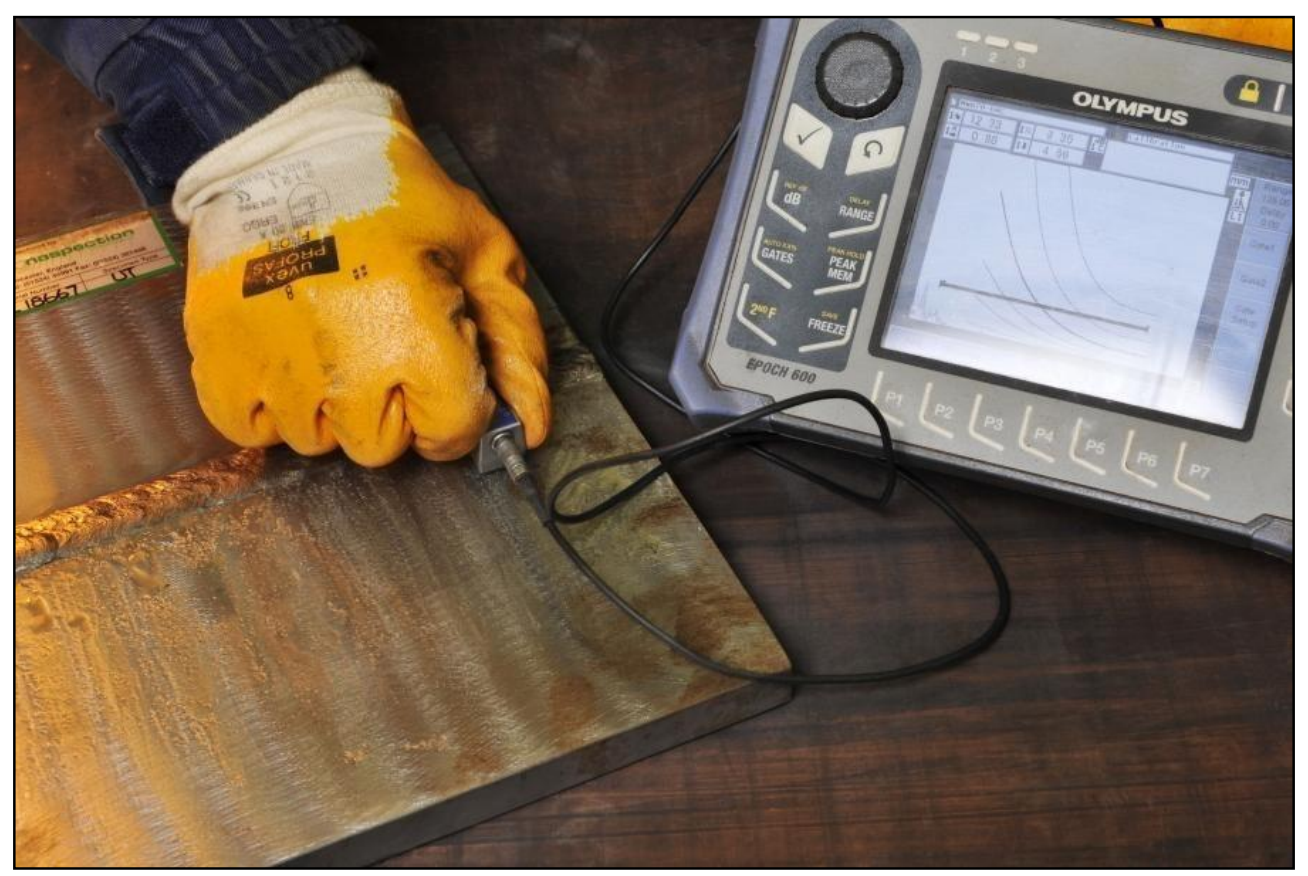

Fig. 1. The Ultrasonic Equipment

First Technique is called Through-Transmission Manner, in this technique we need to use two probes, we call the first one a sender and the second one is a receiver, to determine a composite the two probes need to be placed on both sides, the defect position is the scanning result.

Second Technique called Pitch-Catch technique, this technique in practice used for cylindrical materials, in this technique the ultrasonic waves travelling in shape of angle in the material and reflected back at the same transmitted angle.

Third Technique called Pulse-Echo technique, in this technique one probe only to be used, hence from one side only and to be placed perpendicular to the material and a bunch of ultrasonic waves send through and they are echoed back by the delamination or by reluctant material.

The reflected information of the ultrasonic waves is gathered and exhibited in different shapes yet, there are four general structures are presented in the NDT field as indicated by:

- A-scan: It is a graph, it presents the amount of reflected ultrasonic waves against the time as well as the depth of the defect in $\mathrm{X}$ and $\mathrm{Y}$ axis.

- $\quad$ B-scan: It displays the cross-sectional image of the composite shows the depth of the defect from the surface and it shows the exact position of the defect as well as the capability to detect for any other defects might be underneath previous defect found from C-scan as the ultrasonic waves won't be able to travel thorough defects.

- C-scan: It displays the top view image of the composite shows the number of the defects and the exact position of each defect in term of $\mathrm{X}$ and $\mathrm{Y}$ coordinates.

- $\quad$ S-scan: It displays the area only underneath the probe which is very limited but it is very effective as it is giving more details of every individual defect. 
Phase Array system connected to examine laminated composites is a contact technique, where the test is physically moved over the examined piece[15]. A specific frequency is connected, which can change between $5 \mathrm{MHZ}$ to $10 \mathrm{MHZ}$ yet, any spectacular excess of the frequency can contrarily influence the ultrasonic wave reduction causing a wrong results outcomes[1]. A type of medium called Couplant is actualized between the probe and the surface of a material to beat power waste, which happens while ultrasonic waves venture out from the transducer to the material[3]. Ultrasonic testing NDT technique is a dependable method utilized as a part of composites to distinguish and recognize delamination that can severely impact the life cycle of the materials and lead to catastrophic disaster, particularly in aeronautical industry[12]. In different terms, phase array technique is a technique can be utilized to successfully in laminated composites and examine the depth of the sample.

\subsection{Composite Materials}

Composite materials define as two or more individual material combined together in one structure using pressure, heat and chemicals, as seen in figure (2). A high demand on materials with less weight and high rigidity particularly in aviation industry as the nonhomogenous technology has raised the uniformity and solidity of the products as shown in figure (3)[16]. Composite materials can be classified in to three main types[6, 17]:

- $\quad$ Fiber Reinforced Composites (FRC) are mainly used to manufacturer bulletproof vests and in concrete as a hardening element by adding steel rods to increase the mechanical rigidity.

- Structural Materials are mainly used in aviation industry for its light weight, toughness, fatigue resistance and corrosion resistance made from two or more different types of materials bonded together to produce a rigid laminated materials.

- $\quad$ Practical-Reinforced Composite materials mainly used in civil engineering are consist of one or more materials such as sand and cement for example with some water place in a mold producing a tough material.

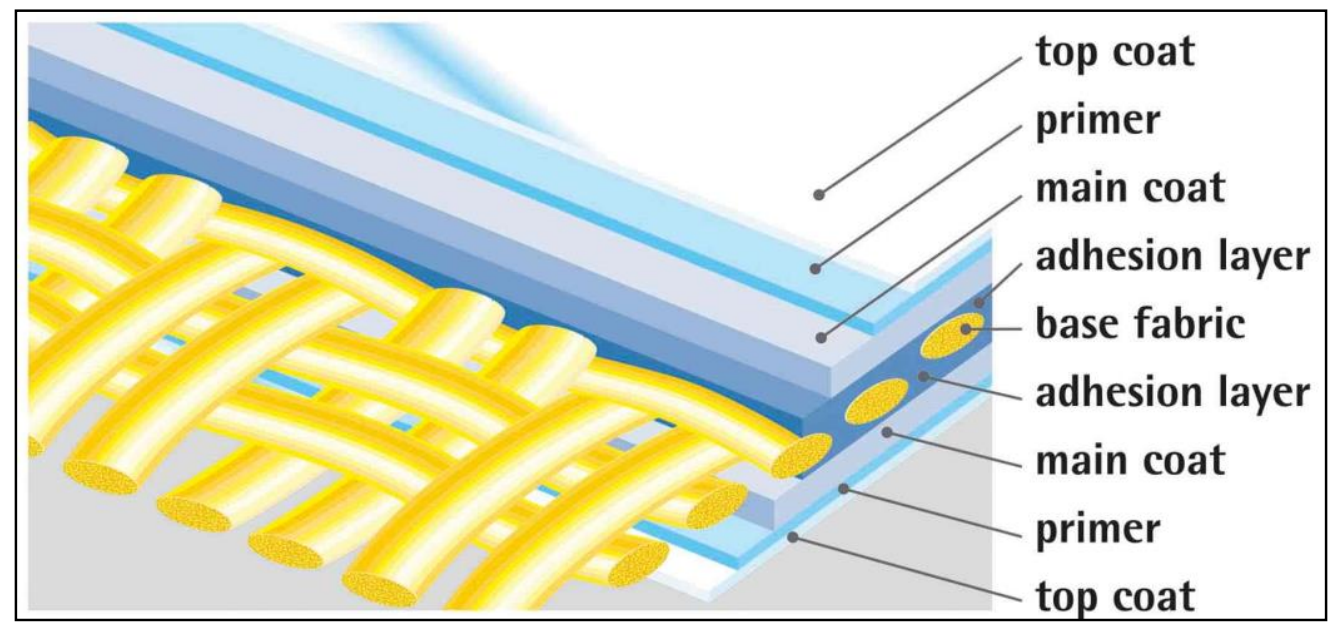

Fig. 2. Composite Materials 


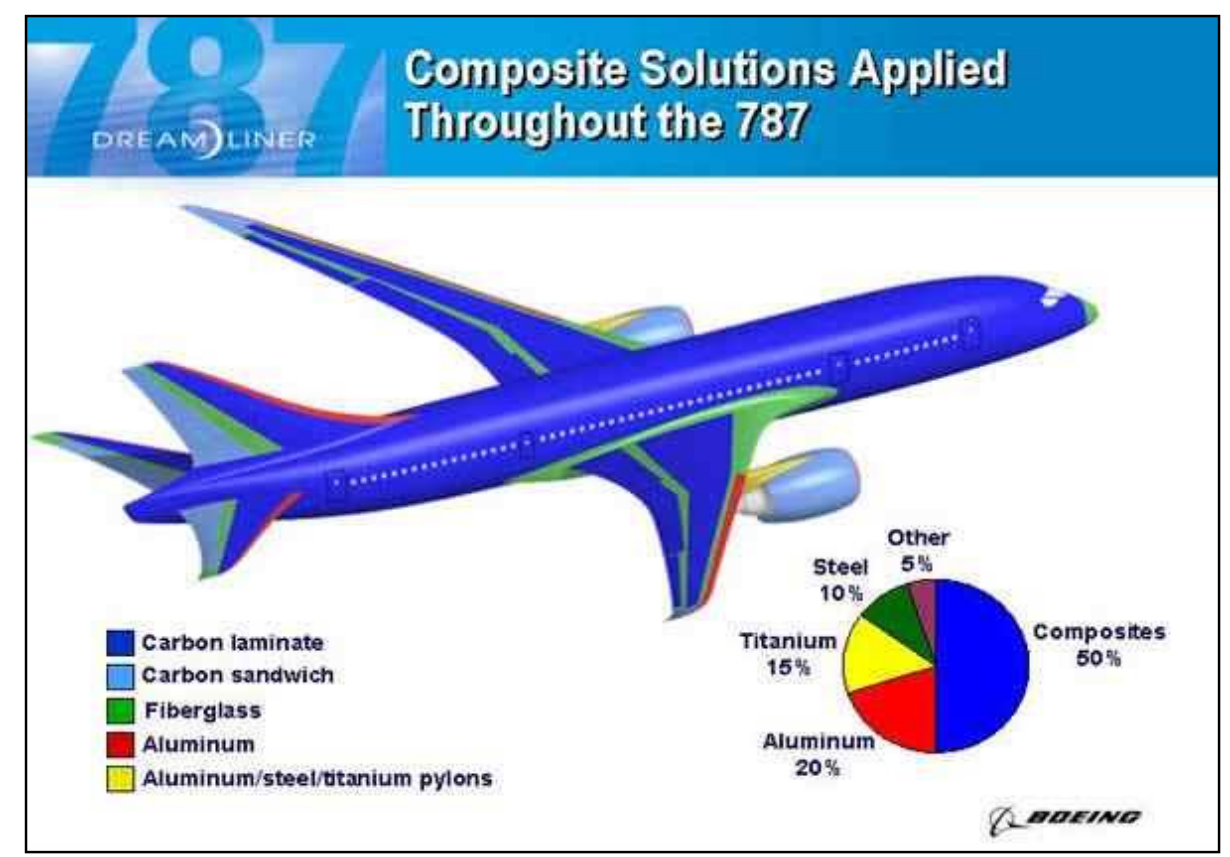

Fig. 3. Composite Materials in Aviation Industry

\subsection{Capabilities:}

The ultrasonic test is appropriate for testing the composite materials for very couple of reasons[18,19]:

- It can decide the size and the area of the defects.

- $\quad$ Resolution modification dislikes the other devices.

- Mobile and reduced, so it is so viable and could be conveyed to the area of the composite to be assessed which is extremely helpful particularly in aeronautical industry as the ultrasonic devices can be used in a work field without the prerequisite of research center condition .

- Ultrasonic test can guarantee composite materials thickness to assure life anticipation.

- The profundity of imperfections along the composite materials can be assessed.

- Ultrasonic test devices can be connected from one side if there is any confinement to get to the composite materials.

- The ultrasonic waves travel in both high density and low density but it will be slower in low density.

\subsection{Limitations:}

There are vary couple of impediments utilizing ultrasonic test on composite materials, such as[20,21]:

- $\quad$ To carry out an effective test, understanding and practicing are required. 
- Thin materials are extremely hard to quantify.

- $\quad$ The composite surface must be spotless and smooth with couplant to be included.

- While the signal travelling from the probe to the surface a power loss may cause an inaccurate outcome.

- $\quad$ In some high level ends they are costly to purchase.

- Once the waves hit the defect it will reflect and we cannot see anything pass the defect.

- Ultrasonic waves won't be able to travel through a vacuum defect as it has a no density.

\subsection{Ultrasonic Laboratory Experiment and Results:}

\subsubsection{Method:}

At the university laboratory we were required to examine a piece of carbon-fibre material made from 10 layers $(10 * 20) \mathrm{cm}$ and $3 \mathrm{~mm}$ thick with Olympus Omni equipment for any defects. The probe we used contains 64 elements and the more elements a higher resolution with $5 \mathrm{MHz}$ frequency, we used a piece called wedge will hold the probe to keep the probe safe then we added a liquid called couplant to help the sound to transmit through different materials which is water based and the water is very conductive of sound plus this couplant would help to fill any gaps and make it smoother, after that we started to move the probe along the material bit by bit to cover the whole surface and get our results as explained in figures (4), (5), and (6).

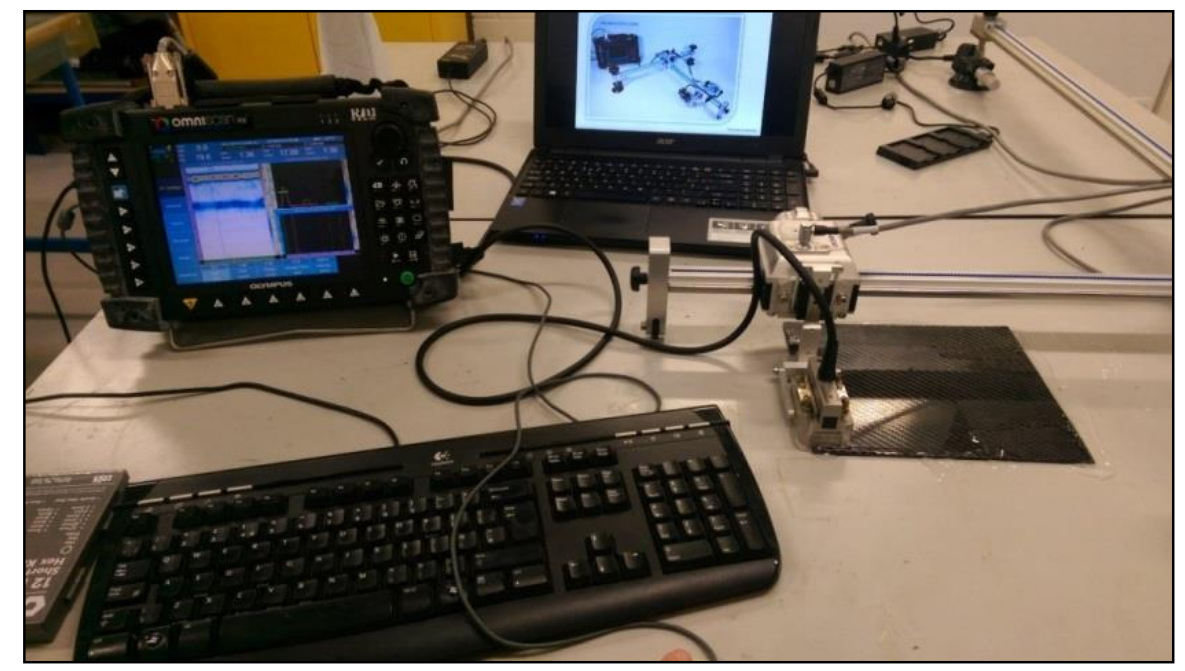

Fig. 4. Olympus Omni, Probe and Carbon-Fibre Spacemen 


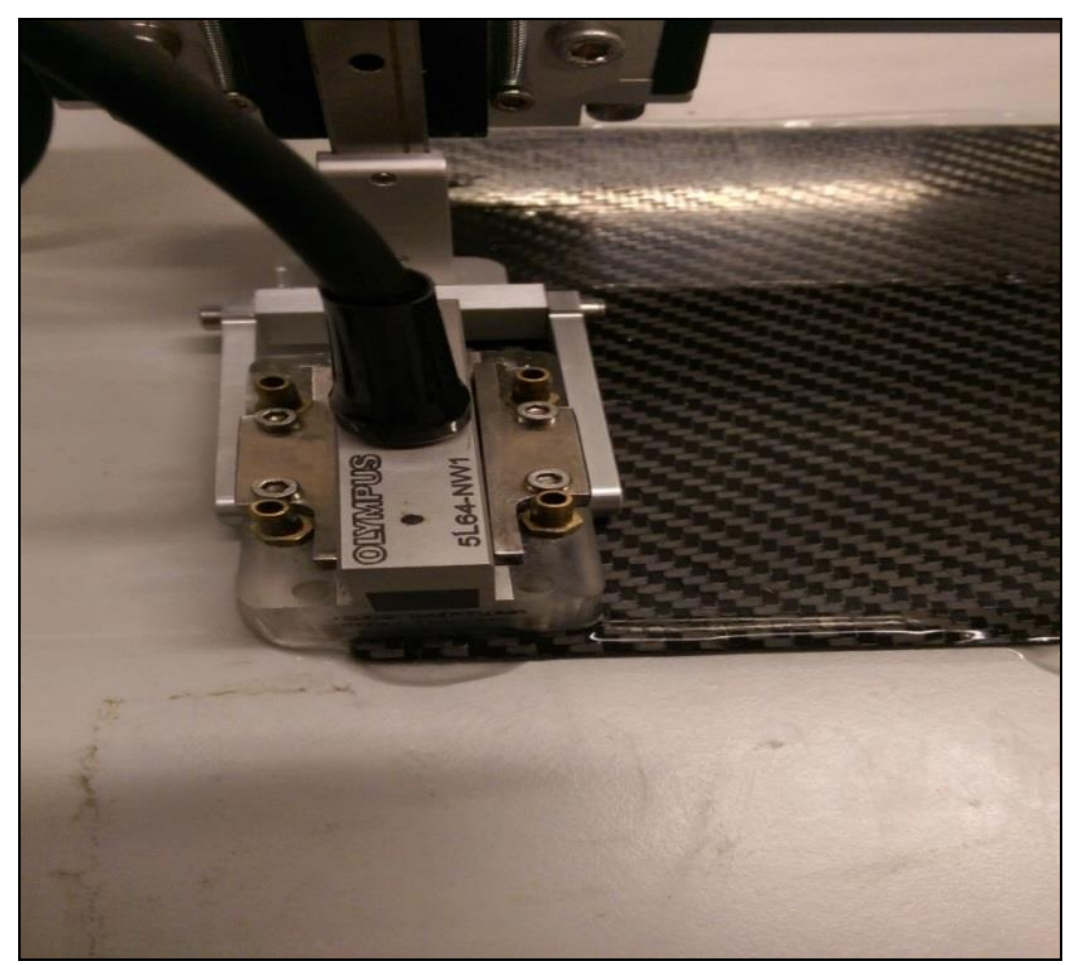

Fig. 5. The Probe

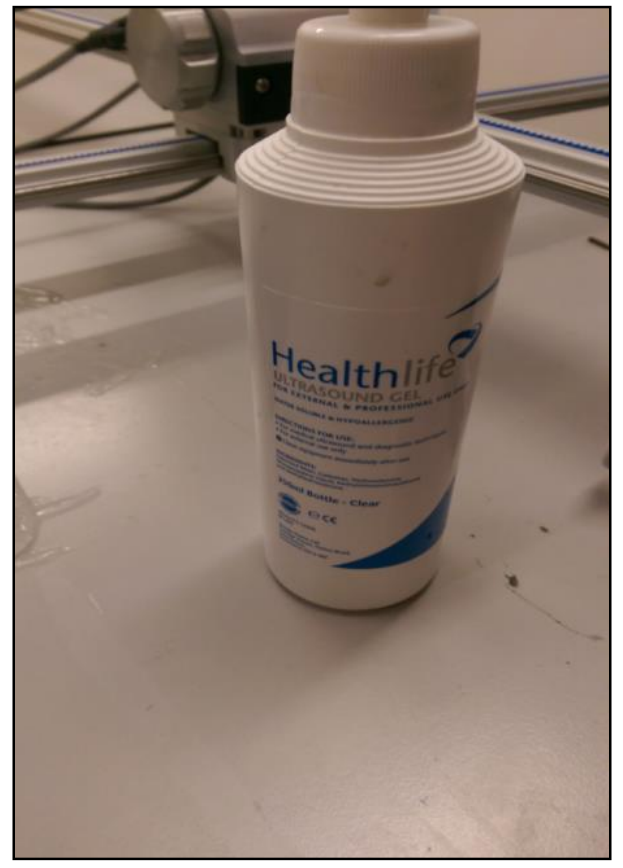

Fig. 6. Couplant

\subsubsection{Results:}

In C-scan we found 5 defects, as seen in figure (7). 


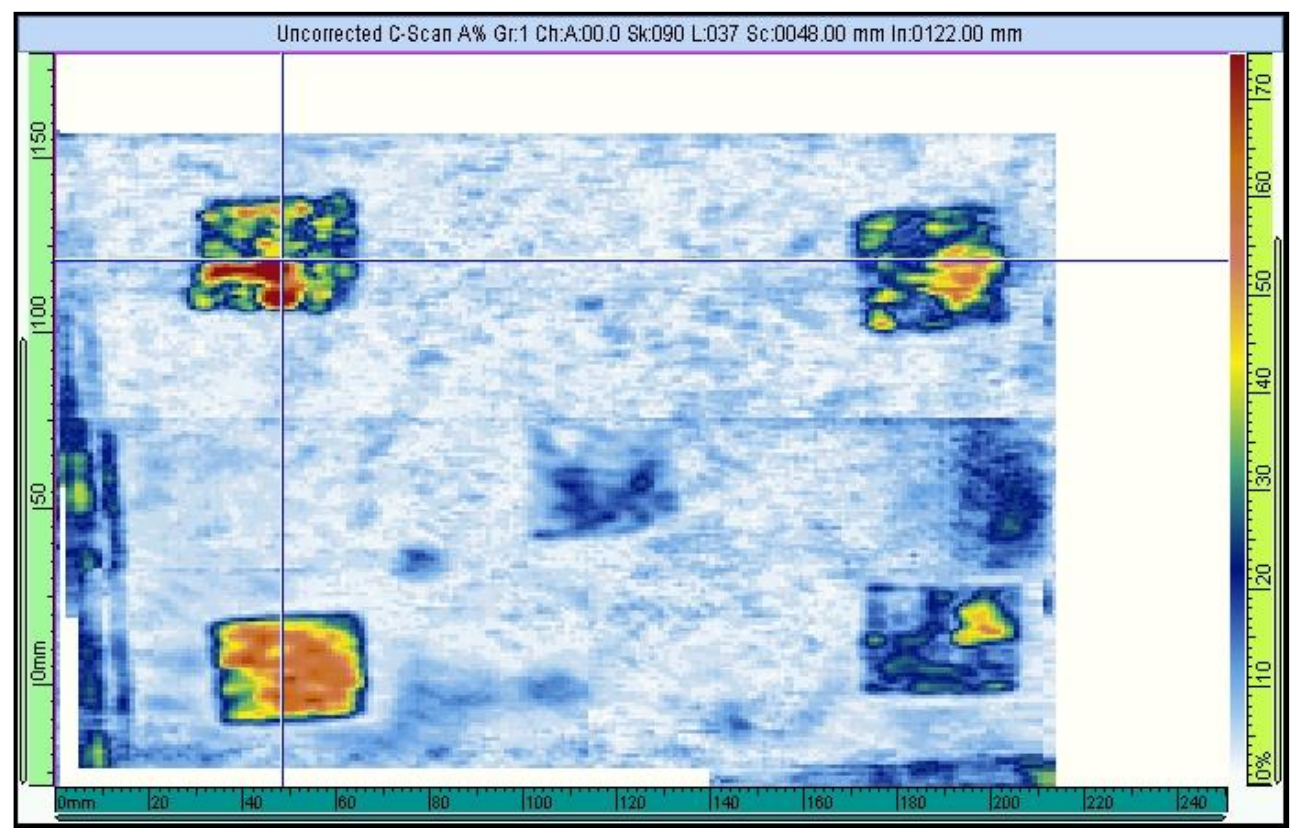

Fig. 7. 5 Defects in C-Scan

Figure (8) shows the $1^{\text {st }}$ defect and the details as follows:

- A-Scan shows the defect is $0.25 \mathrm{~mm}$ from the surface and the frequency bounced quicker.

- $\quad$ B-Scan shows the position of the defect which is around $0.25 \mathrm{~mm}$ from the top surface and around $16 \mathrm{~mm}$ from the right hand edge.

- $\quad$ C-Scan shows the number of the defects and their position.

- $\quad$ S-Scan shows the size of the defect and $0.25 \mathrm{~mm}$ from the top surface.

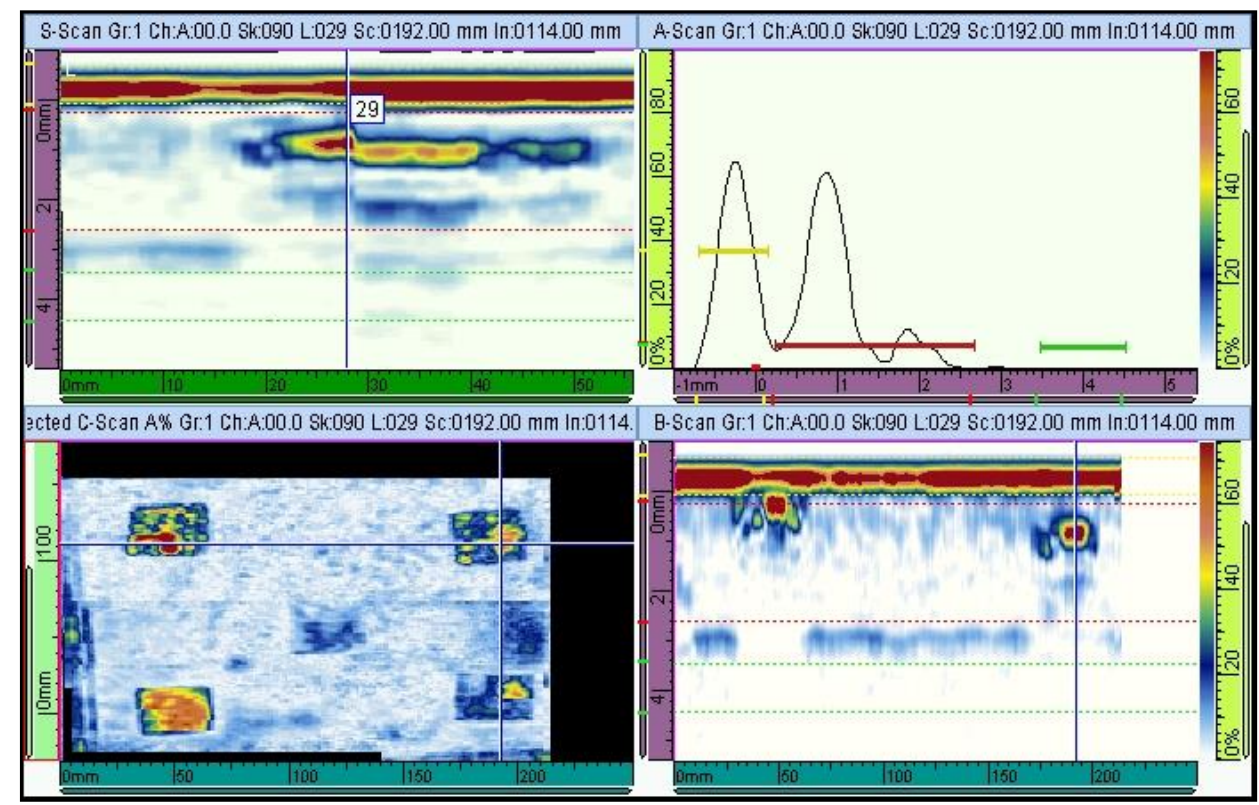

Fig. 8. Defect No.1 
Figure (9) shows the $2^{\text {nd }}$ defect, details as follow:

- $\quad$ A-Scan shows which is $2 \mathrm{~mm}$ from the top surface and the frequency took much longer time.

- $\quad$ B-Scan shows which is around $2 \mathrm{~mm}$ from the top surface and around $83 \mathrm{~mm}$ from the right hand edge.

- $\quad$ C-Scan shows the number of the defects and their position.

- $\quad$ S-Scan shows the size of the defect and $2 \mathrm{~mm}$ from the top surface.

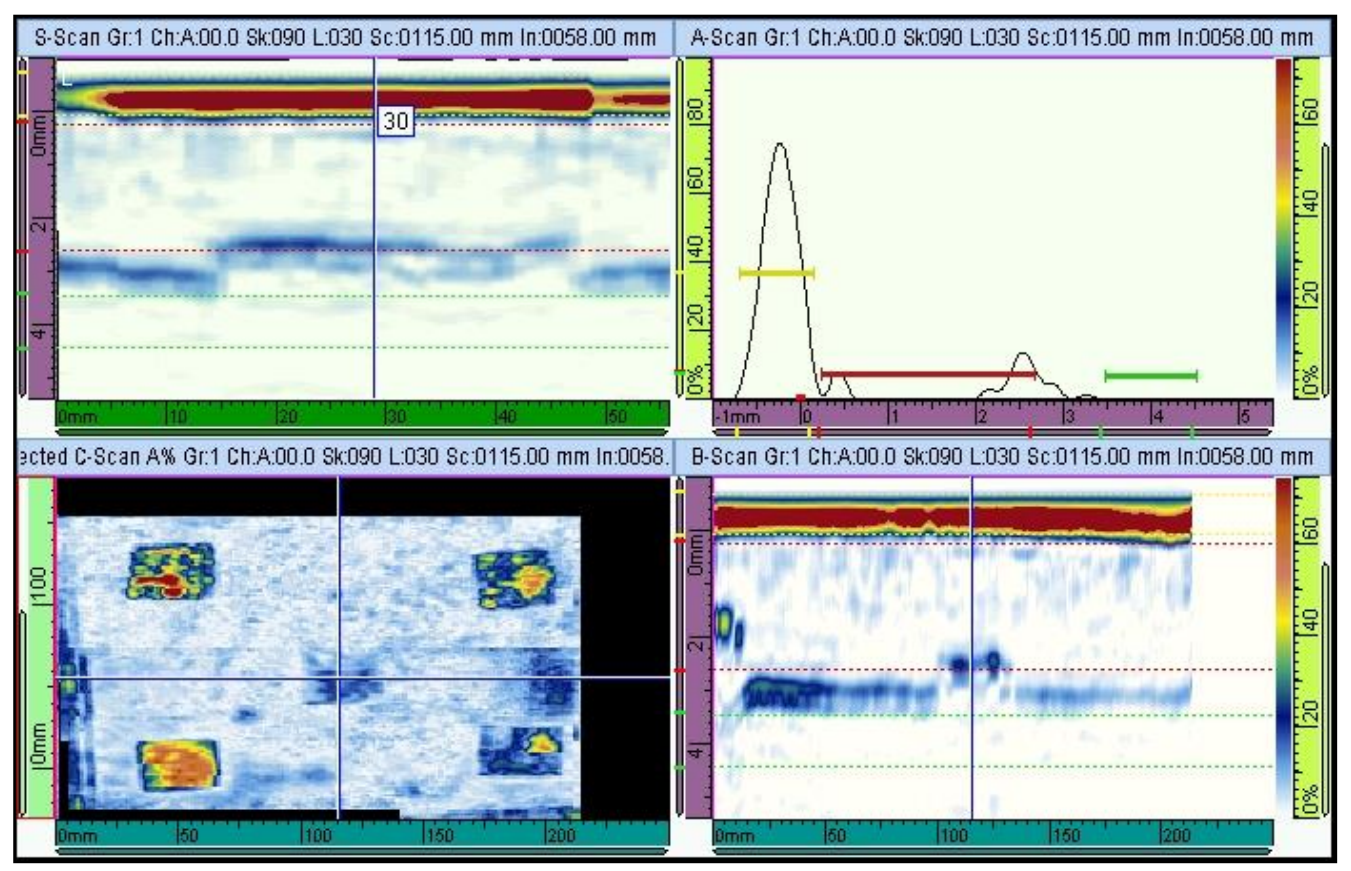

Fig. 9. Defect No.2

Figure (10) shows the 3rd defect, details as follow:

- $\quad$ A-Scan shows which is around $1.3 \mathrm{~mm}$ from the top surface and the frequency took even much longer time.

- $\quad$ B-Scan shows which is around $1.3 \mathrm{~mm}$ from the top surface and around $35 \mathrm{~mm}$ from the left hand edge.

- $\quad$ C-Scan shows the number of the defects and their position.

- $\quad$ S-Scan shows the size of the defect and $1.3 \mathrm{~mm}$ from the top surface. 


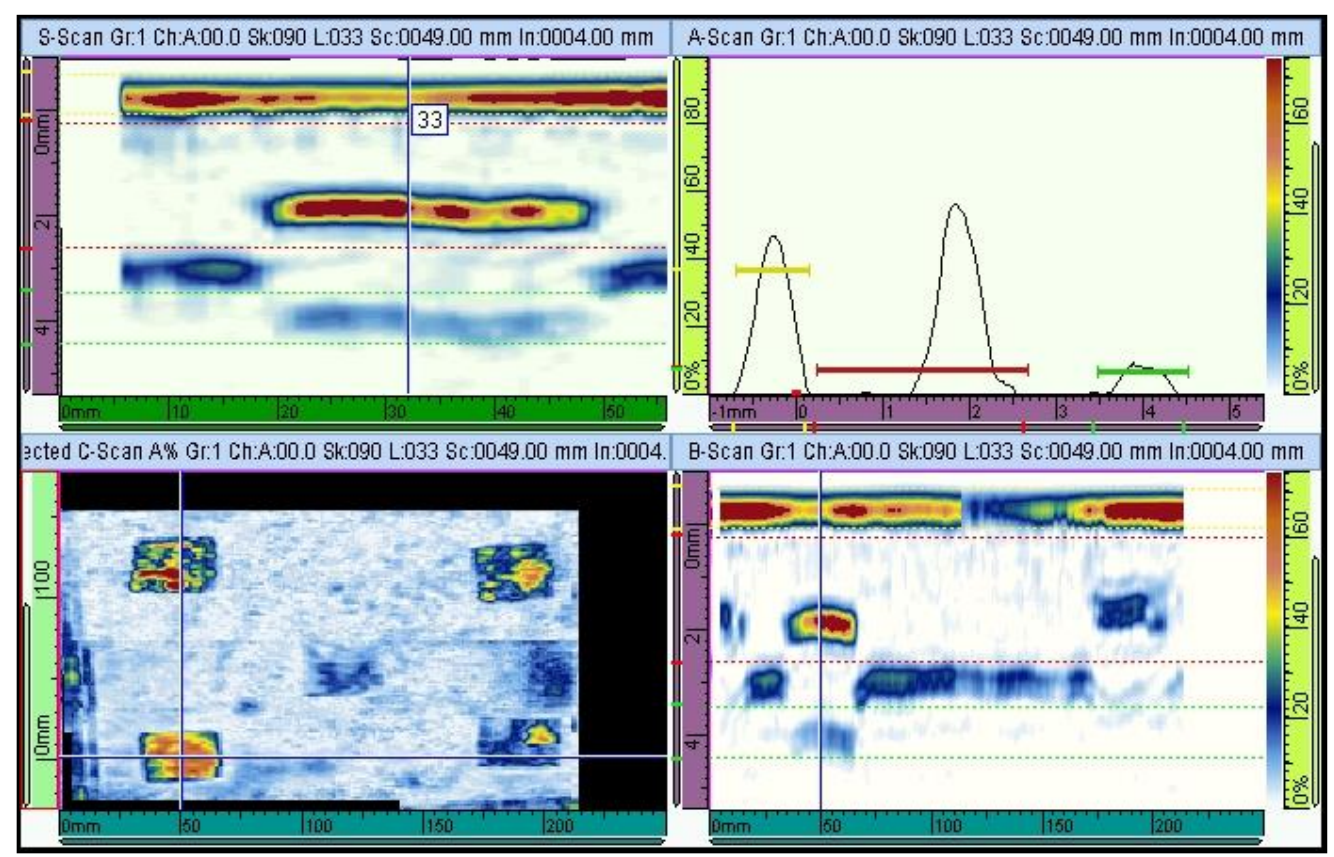

Fig. 10. Defect No.3

Figure (11) shows the 4th defect, details as follow:

- $\quad$ A-Scan shows is around $1.1 \mathrm{~mm}$ from the top surface and the frequency took enough time to bounce.

- $\quad$ B-Scan shows which is around $1.1 \mathrm{~mm}$ from the top surface and around $8 \mathrm{~mm}$ from the right hand edge.

- $\quad$ C-Scan shows the number of the defects and their position.

- $\quad$ S-Scan shows the size of the defect and $1.1 \mathrm{~mm}$ from the top surface.

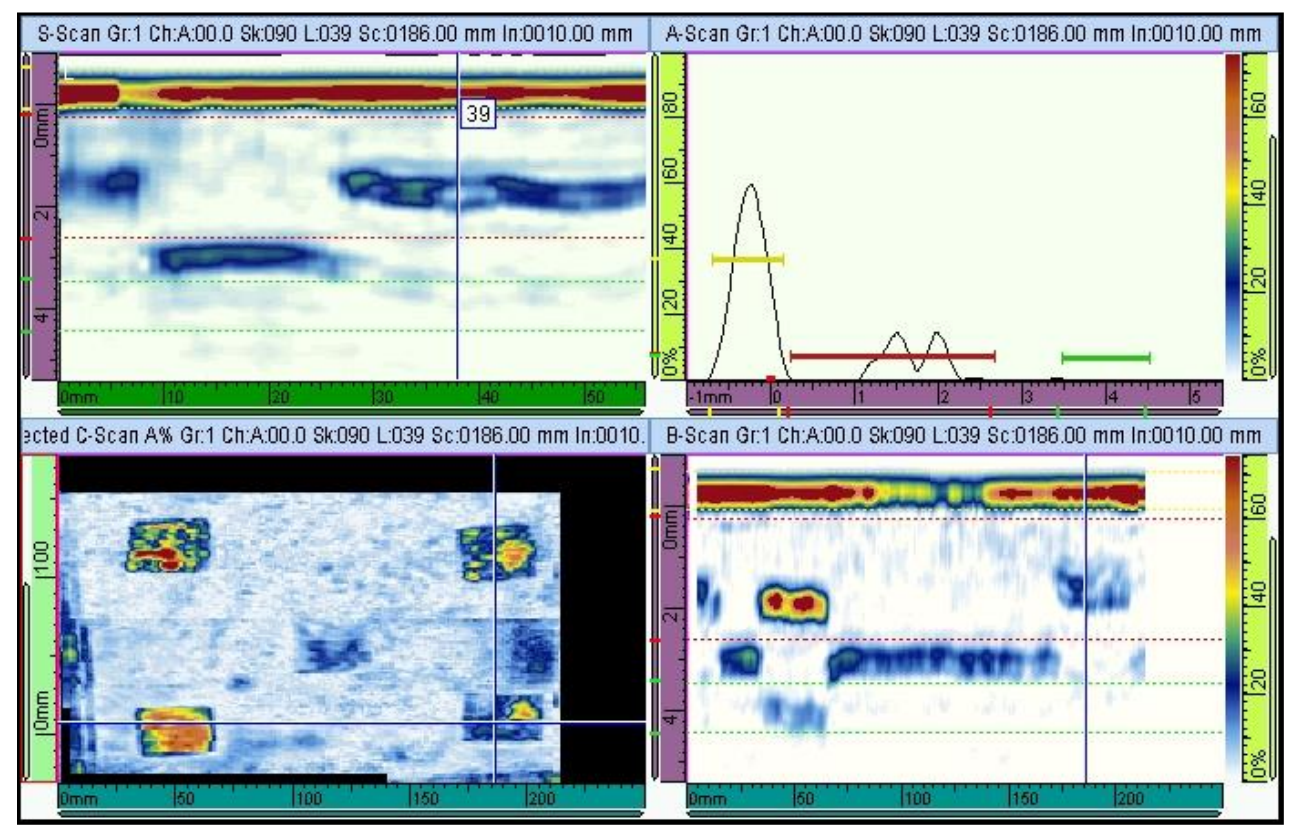

Fig. 11. Defect No.4 
Figure (12) shows the 5th defect, details as follow:

- $\quad$ A-Scan shows is around $0.02 \mathrm{~mm}$ from the top surface and the frequency took enough time to bounce.

- $\quad$ B-Scan shows which is around $0.02 \mathrm{~mm}$ from the top surface and around $30 \mathrm{~mm}$ from the left hand edge.

- $\quad$ C-Scan shows the number of the defects and their position.

- $\quad$ S-Scan shows the size of the defect and $0.02 \mathrm{~mm}$ from the top surface.

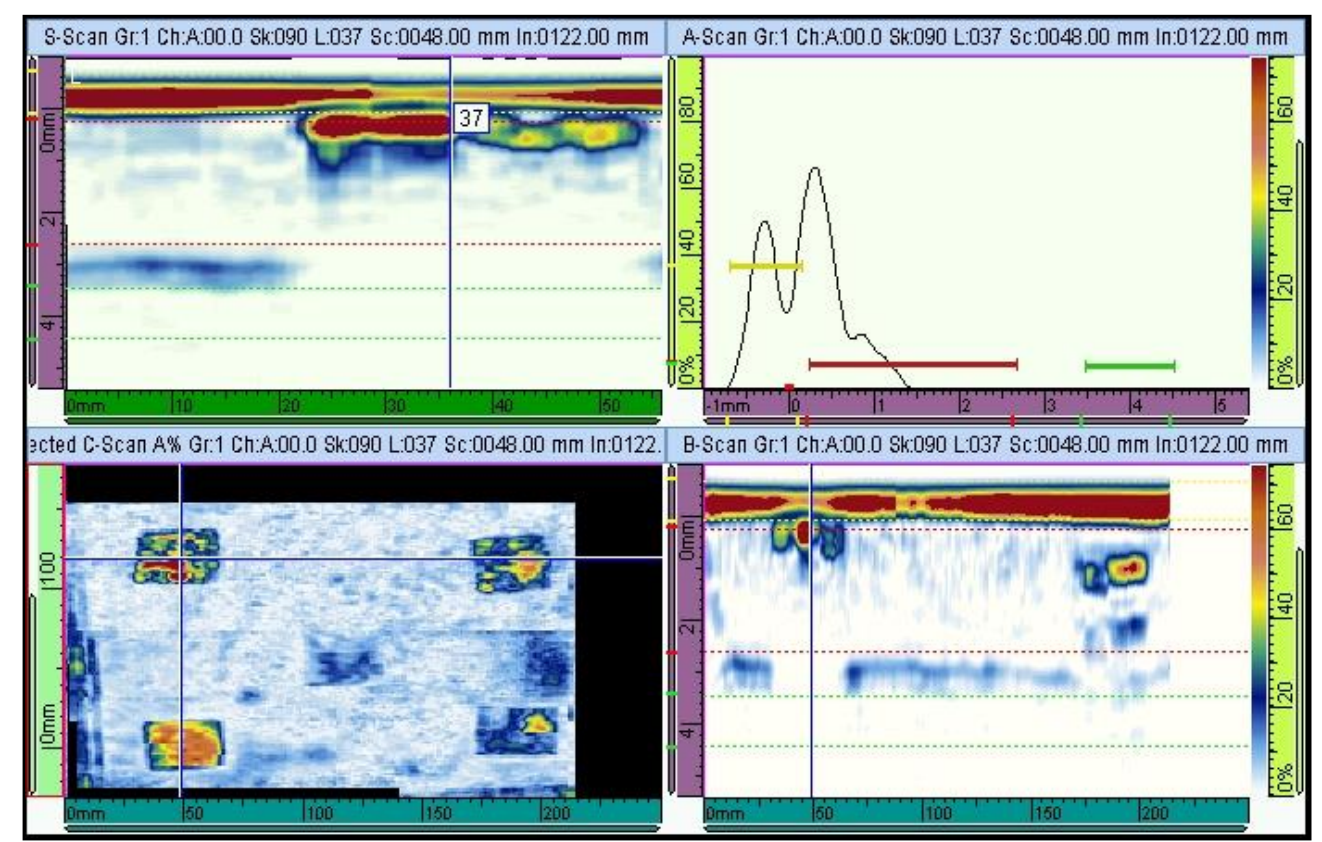

Fig. 12. Defect No.5 


\subsubsection{Omni Scan Report:}

Table 1. Omni Scan Report

\begin{tabular}{|llllll|}
\hline Report Date & Report Version & Setup File Name & Inspection Date & Inspection Version & Save Mode \\
2018 / 04 / 30 & MXU - 2.0R27 & 3MM_COMPOSITE_5L64NW1.ops 2018/04/30 & MXU - 2.0R27 & Report \\
OmniScan Type & OmniScan Serial \# & Module Type & Module Serial \# & Calibration Due & Data File Name \\
OmniScan MX & OMNI-101144 & OMNI-M-PA16128 & OMNI-200577 & $2010 / 06 / 25$ & team 5.opd \\
\hline
\end{tabular}

Group 1

Setup

\begin{tabular}{|c|c|c|c|c|c|}
\hline \multicolumn{6}{|l|}{ A:00.0 Sk:090 L:001 } \\
\hline Beam Delay & Start (Half Path) & Range (Half Path) & Max. PRF & Type & Averaging Factor \\
\hline 17.76 us & $-1.00 \mathrm{~mm}$ & $6.40 \mathrm{~mm}$ & 105 & PA & 1 \\
\hline Scale Type & Scale Factor & Video Filter & Pretrig. & Rectification & Band-Pass Filter \\
\hline Compression & 1 & On & $0.00 \mu \mathrm{s}$ & FW & None $(0.54-22 \mathrm{MHz})$ \\
\hline Voltage & Gain & Mode & Wave Type & Sound Velocity & Pulse Width \\
\hline 40 (Low) & $0.00 \mathrm{~dB}$ & PE (Pulse-Echo) & User-Defined & $4000.0 \mathrm{~m} / \mathrm{s}$ & $100.00 \mathrm{~ns}$ \\
\hline Scan Offset & Index Offset & Skew & & & \\
\hline $0.00 \mathrm{~mm}$ & $0.00 \mathrm{~mm}$ & $90.0^{\circ}$ & & & \\
\hline Gate & Start & Width & Threshold & Synchro & \\
\hline I & $-0.72 \mathrm{~mm}$ & $0.84 \mathrm{~mm}$ & $37.00 \%$ & Pulse & \\
\hline A & $0.22 \mathrm{~mm}$ & $2.42 \mathrm{~mm}$ & $8.00 \%$ & Pulse & \\
\hline B & $3.44 \mathrm{~mm}$ & $1.04 \mathrm{~mm}$ & $7.00 \%$ & Pulse & \\
\hline TCG Point Number & Position (Half-Path) & Gain & & & \\
\hline 1 & $0.00 \mathrm{~mm}$ & $0.0 \mathrm{~dB}$ & & & \\
\hline
\end{tabular}

\section{Calculator}

\begin{tabular}{|lllll|}
\hline Used Element Qty. & First Element & Last Element & Resolution & Wave Type \\
8 & 1 & 64 & 1.0 & User-Defined \\
Start Angle & Stop Angle & Angle Resolution & Focal Depth & Law Configuration \\
$0.0^{\circ}$ & N/A & N/A & $20.00 \mathrm{~mm}$ & Linear at $0^{\circ}$ \\
\hline
\end{tabular}

\begin{tabular}{|c|c|c|}
\hline Material & Geometry & Thickness \\
\hline PLEXIGLAS & Plate & $4.00 \mathrm{~mm}$ \\
\hline
\end{tabular}

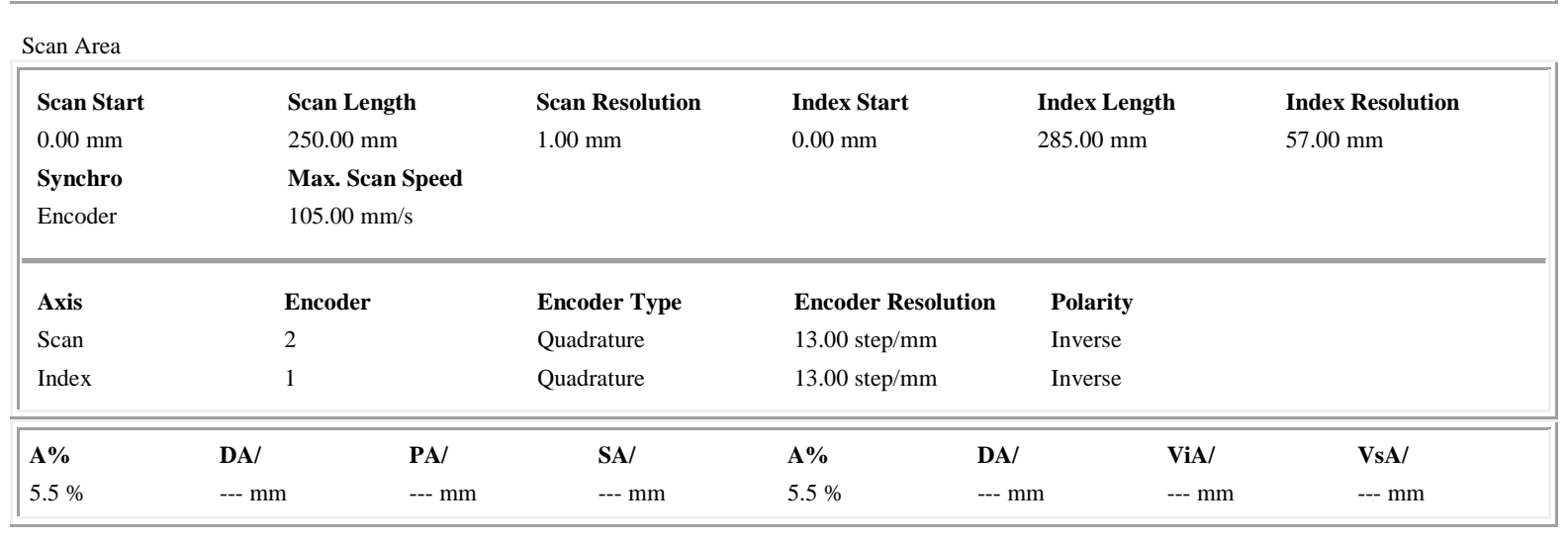

\section{Conclusion and Recommendation:}

As should be obvious from the examination has been done that the Non-Destructive Test technique is the most appropriate strategy for testing any materials and the composite materials as we utilized the ultrasonic review strategy, yet this technique was not ideal 
strategy for this test as it has very couple of confinements restricting this technique to be an extraordinary technique in NDT. Our proposal is to pick the most appropriate NDT strategy as each material and composite materials have its own particular properties and in addition the assessment strategies had its own particular capabilities and limitations.

\section{References}

[1] Salchak, Y., Zhvyrblya, V., Sednev, D., and Lider, A. (2016) Digitally focused array ultrasonic testing technique for carbon fiber composite structures, IOP Conference Series: Materials Science and Engineering, 135.

[2] Nesvijski, E. (1999) Phase Ultrasonic Testing of Joints in Multilayered Composite Materials. Journal of Thermoplastic Composite Materials, 12(2), pp.154-162.

[3] Gryzagoridis, J. (1989) Holographic non-destructive testing of composites, Optics \& Laser Technology, 21(2), pp.113-116.

[4] Shen, Q., Omar, M., and Dongri, S. (2011) Ultrasonic NDE Techniques for Impact Damage Inspection on CFRP Laminates. Journal of Materials Science Research, 1(1), pp.3-14.

[5] Kamsu-Foguem, B. (2012) Knowledge-based support in Non-Destructive Testing for health monitoring of aircraft structures, Advanced Engineering Informatics, 26(4), pp.859-869.

[6] Reithmaier, L. and Sterkenburg, R. (2014) Standard aircraft handbook for mechanics and technicians, $7^{\text {th }}$ edition, McGraw-Hill Education.

[7] Sharpe, R. (1976) Non-destructive testing, Non-Destructive Testing, 9(1), p.55.

[8] Thabit, Thabit H. (2013) Adoption the Fuzzy Logic to Enhance the Quality of the Accounting Information to Operate Balanced Scorecard - Applied on Mosul Bank for Development \& Investment in Nineveh Province, M.Sc. thesis in accounting, University of Mosul, Mosul, Iraq.

[9] Thabit, Thabit H., and Jasim, Yaser A. (2015) A Manuscript of Knowledge Representation, International Journal of Social Sciences \& Economic Environment, Vol.1, Issue 1, pp. 44-55.

[10] Thabet, S., and Thabit, Thabit H. (2018) Computational Fluid Dynamics: The Science of Future, International Journal of Research and Engineering, Vol.5, No. 6, pp. 430-433

[11] Thabet, Senan, and Thabit, Thabit H. (2018) CFD Simulation of the Air Flow around a Car Model (Ahmed Body), International Journal of Scientific and Research Publications, 8(8).

[12] Krautkrämer, J., and Krautkrämer, H. (1983) Ultrasonic Testing of Materials, Berlin, Heidelberg: Springer Berlin Heidelberg.

[13] Raj, B., Jayakumar, T., and Thavasimuthu, M. (2008) Practical non-destructive testing, Oxford, U.K.: Alpha Science International.

[14] Thabit, Thabit H., and Younus, Saif Q. (2018) Risk Assessment and Management in Construction Industries, International Journal of Research and Engineering, Vol. 5, No. 2, pp. 315-320. 
[15] Bouden, T., Djerfi, F., and Nibouche, M. (2015) Adaptive split spectrum processing for ultrasonic signal in the pulse echo test, Russian Journal of Nondestructive Testing, 51(4), pp.245-257.

[16] Bates, C. (1969) Non-destructive testing techniques, Non-Destructive Testing, 2(1), pp.55.

[17] Thabet, Senan, Thabit, Thabit H., and Jasim, Yaser A. (2018), CFD Analysis of a Backward Facing Step Flows, International Journal of Automotive Science and Technology, Vol.2 , No.3, pp.10-16.

[18] Berthelot, J. (2009) Damping Analysis of Sandwich Composite Materials, Journal of Composite Materials.

[19] Halmshaw, R. (1991) Non destructive testing, London.

[20] Hoagland (1979) Storage Technology: Capabilities and Limitations, Computer, 12(5), pp.12-18.

[21] Schall, W. (1968) Non-destructive testing, Brighton: Machinery Pub. 